الميئات التنغيميّة للوقف الصوتيَّ فهي سورة العاديات

(دراسة مخبرية)

د. بشره عبد الرزاق العذاريّ

الجامعة المستنصرية / كلية التربية - قسم اللغة العربية

\title{
b2011a2010@yahoow.com
}

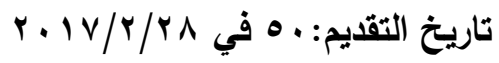

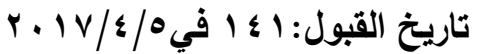

الملخص:

يعالج هذا البحث موضوع الهيئات التتغيميّة للوقف الصوتيّ من جانبيها الوظيفّي والفيزيائّي، وقد اتخذ من فن

سورة العاديات أنموذجًا، فجاء في ثلاثة مباحث: تتاول أولهما، طريقة قياس الهيئات التتغيميّة للوقف أكوسنيكيًا، وتوقف ثانيهما على تزمين الوقف في النصّ اللغويّ، وتتاول ثالثهما، التحليل الوظيفّي والفيزيائّي للهيئات التتغيميّة

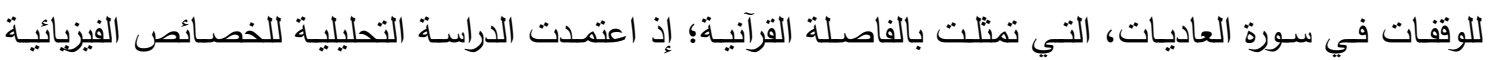

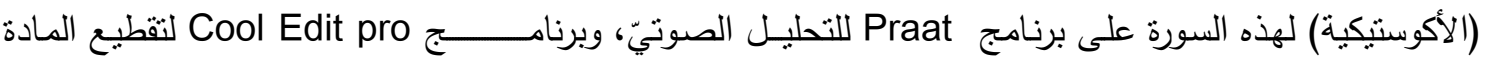

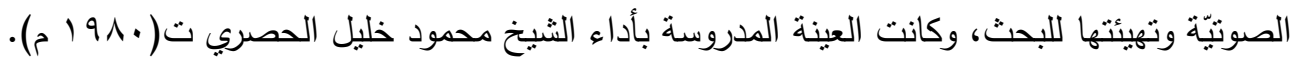
الكلمات المفتاحية: الهيئات التتغيمية، الوقف الصوتي، سورة العاديات، الدراسة المختبرية.

\section{The Intonation Patterns to The Vocal PauseIn Surat Al-Adiyat}

- Study laboratory-

\author{
Dr. BushraAbdulrazzaqmohammed \\ Mustansiriyah University - College nof Education
}

\section{Abstract:}

This research deals with the subject of The Intonation Patterns to The Vocal Pause of its sides functional and physicist, was taken from al-adiyat a model, came in three sections: The first, how to measure The Intonation Patterns to The Vocal Pause acoustic , stopping second on Time tempo to Pause in linguistic text, eat a third of whom, phonetics and physical analysis The Intonation Patterns to The Vocal Pause in Surat Antiquities, which consisted of Quranic comma. It adopted an analytical study of the physical properties (acoustic) of this Surah on Praat voice analysis program, and the program Cool Edit pro for cutting art audio and configured to search, and the sample is studied the performance of Sheikh Mahmoud Khalil exclusive (1980).

Key words: Tantal bodies, vocal endowment, Surat Al-Adiyat, laboratory study. 
المقدمة:

يـرى اللغويـون العرب أنَّ أهميـة الوقف لا تقتصـر على الفصـل بـين المقاطع، في نهايـة

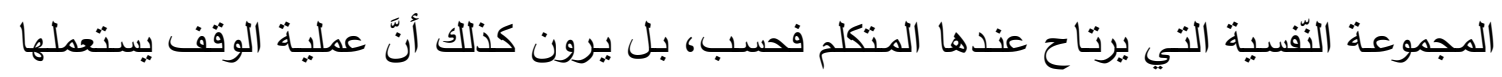

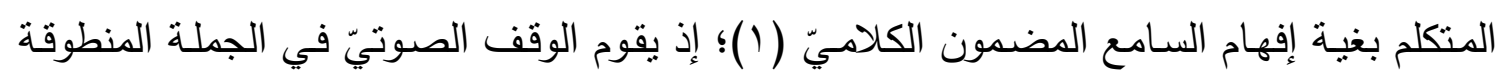

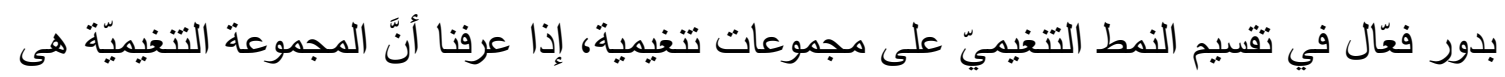

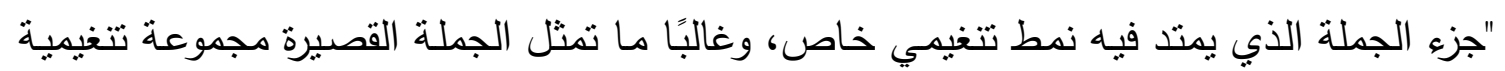

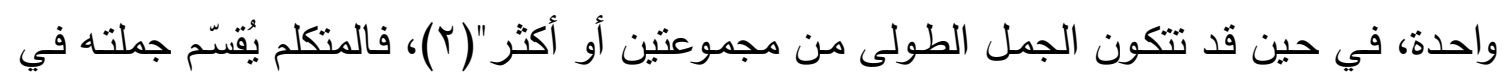

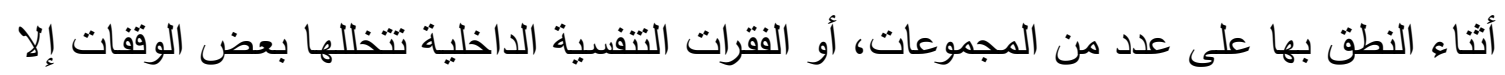

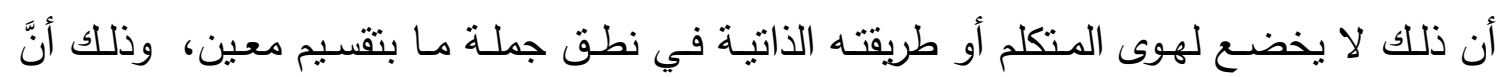

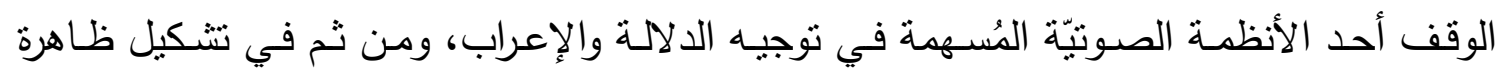
التتغيم.

مدّا تقدم ينتين أنّ للوقف معايير متعددة ومتتوعة، فقد يكون المعيار مؤشرًا تتغيميًّا، وقد يكون

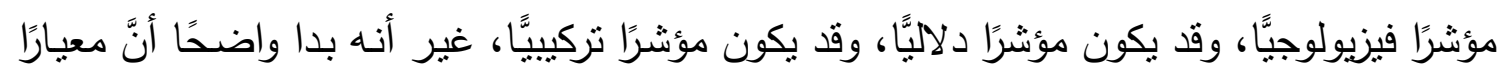

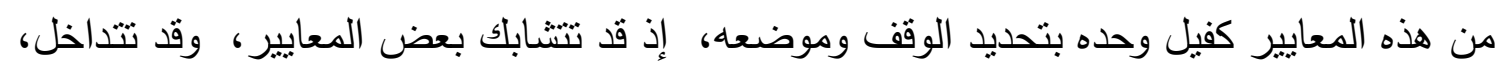

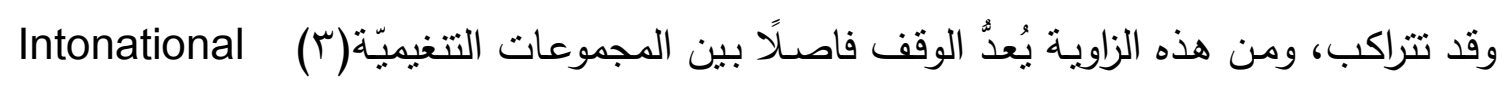
(Groups)

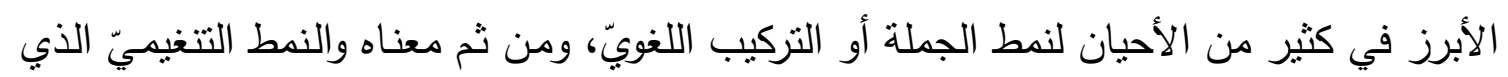

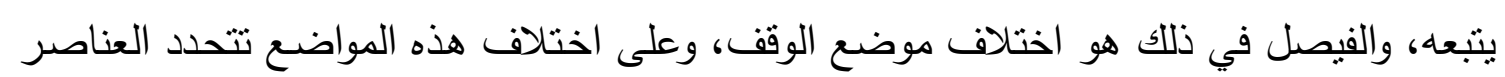

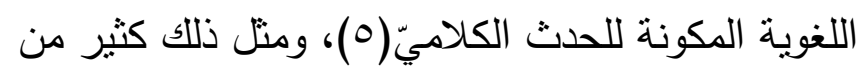
النماذج التحليلية من العبارات القرآنية التي تتاولها علماء القراءات بالتقطيع في ضوء المعنى، التي

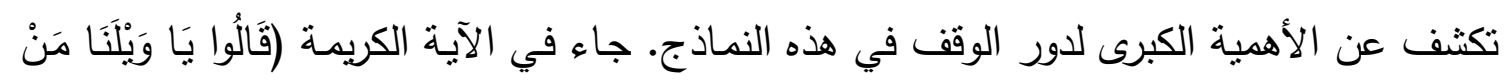

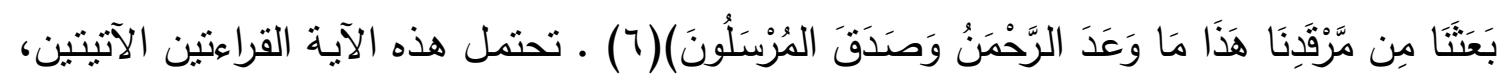

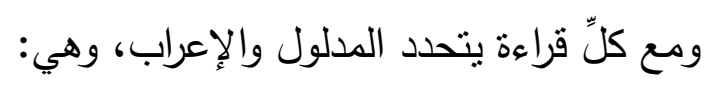

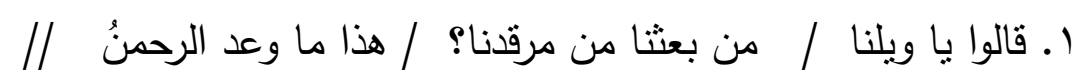
(وقف بنغمة هابطة) (وقف بنغمة مستوية) (وقف بنغمة مستوية) إذ ورد الوقف على قوله (مَرقدنا) والابتداء بقوله: (هذا ما وعد الرحمن) وعلى هذا يكون

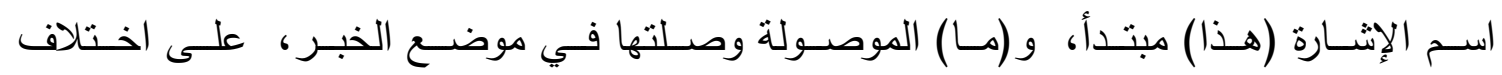

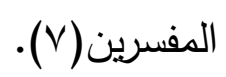


r. قالوا يا ويلنا / من بعثا من مرقدنا هذا / ما وعد الرحمن.. / |

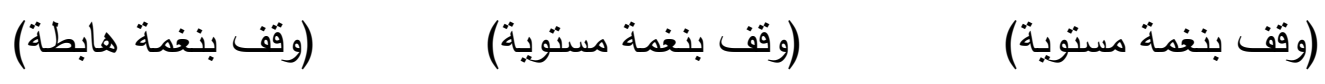

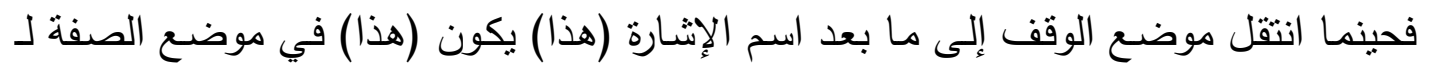
(مرقدنا)، و (ما) الموصولة وصلتها خبر مبتدأ محذوف، تقديره: هذا ما وعد الرحمن، أو مبتدأ خبره

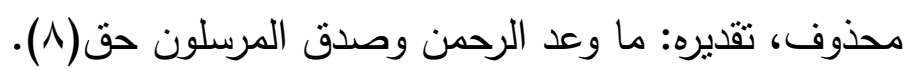

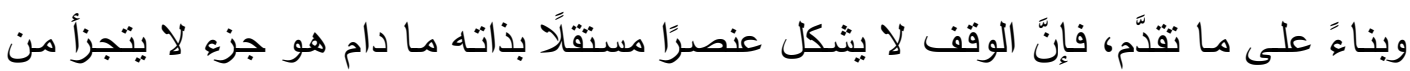

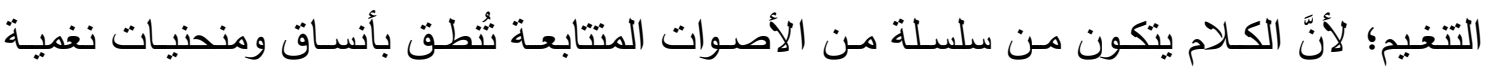
مختلفة، تتزاوح بين الصعود

والاستواء والهبوط في درجة الصوت، وإنَّ معظم هذه الأصوات اللغوية يحدثها تيار من الهواء

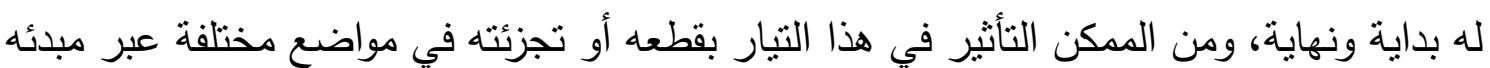
ومنتهاه(9). وهكذا اقترن الوقف بالهجموعة التتغيميّة، أو بالمركب الفونولوجّي، إذ جاء "للوقف دورًا

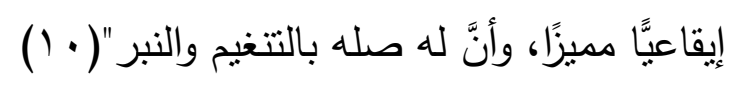

المبحث الأول/ طريقة قياس الهيئات التنغيميّة للوقف أكوستيكيًا:

$$
\text { أ- برامج الدراسة التحليلية }
$$

اعتمد البحث في الدراسة التطبيقية على البرامج الحاسوبية الآتية:

1 - برنامج كول إدت (cool edit pro 2.00): واستعمل في تقطيع الملف الصوتيّ بحسب الطلب، وقياس المدى الزمني لأنواع الوقفات الصوتيّة بالثانية وأجزائها. ץ- برنامج برات (Praat): واستعمل لمعرفة الهيئة التتغيميّة للوقف الصوتيّ، من طريق قياس مستوى درجة النغمة عند بداية المجموعة التتغيميّة ومستواها عند النهاية(الوقف). r- برنامج سنكيت ( 10 snagit.10): واستعمل لنصوير النماذج المحلة والمقاسة في برامج التحليل الصوتيّ (برات، وكول ايدت) والتعليق عليها بالكتابة أو الإشارات. ب- طريقة التحليل الأكوستيكّي للهيئات التنغيميّة للوقف الصوتيّ. اعتمدت الدراسة في هذا المبحث على رصد هيئة الوقف في الفاصلة القرآنية، وقياس المدى الزمني

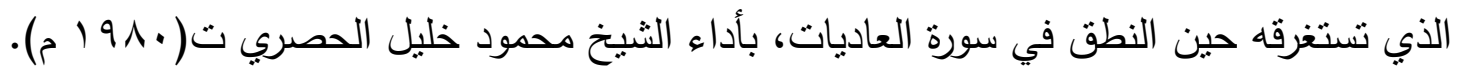
المبحث الثاني/ تزمين الوقف في النصّ اللغويّ: 
إنَّ الفحص الآلـي لتغيرات المدة الزمنية للأصـوات الكلاميـة أظهر فروقًا جديرة بالاهتمـام،

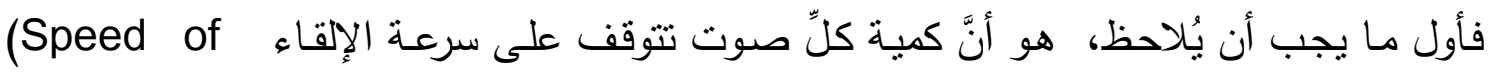
(Delivery) ذللك فددة الأصوات الكلامية تعتمد على طول المجموعة المنطوقة( (1). أما الدور الفعال الذي يقوم بـه الوقف الصوتيّ في تقسيم النص المنطوق على مجموعات

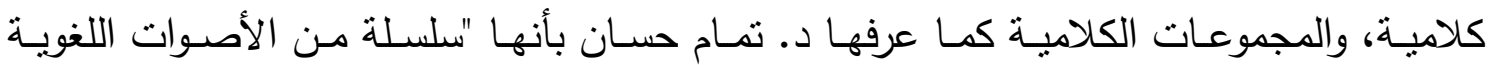

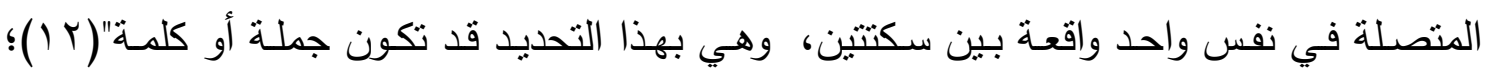
فيمكن معرفتها عن طريق الارتكاز على بعض المعايير الفونولوجية وهو أمر كافٍ لتعيين بدايات

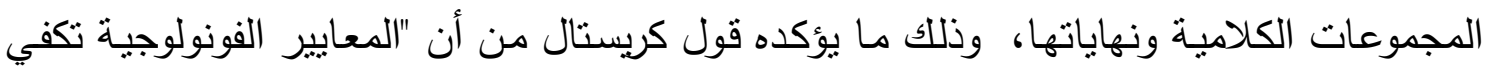

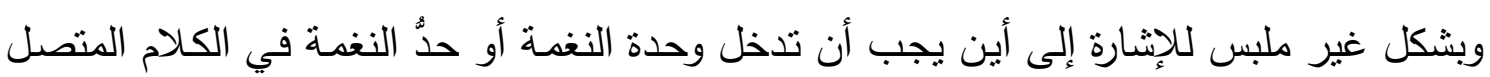

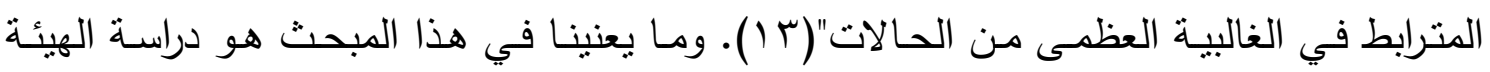

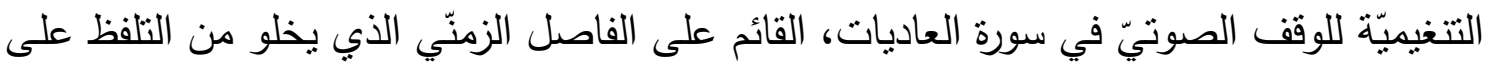

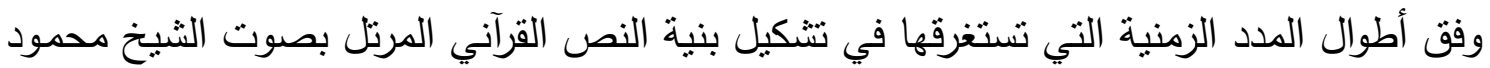

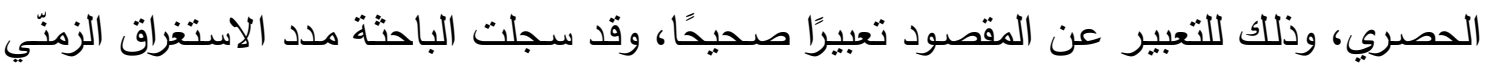
للوقف في الفاصلة القرآنية، وعملت إحصاءات بذللك، سنقف عليها فيما سيأتي. المبحث الثالث/ الهيئات التنغيميّة للوقفات في سورة العاديات:

عند تحليل الهيئات التنغيميّة للوقف في سورة العاديات وجدنا ما يأتي: 1- سير الآيات من(1-0)، في قولهه تعالى: (والعاديات ضبحاً . فالموريات قدحاً . فالمغيرات

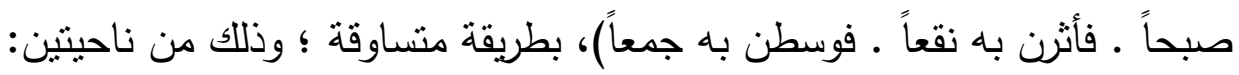

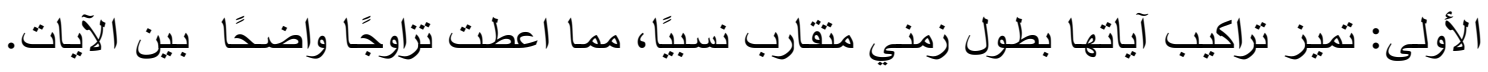

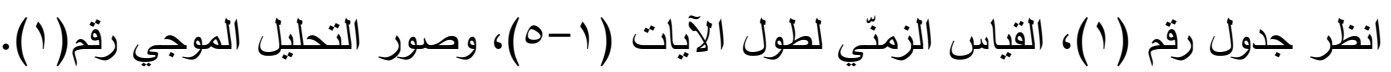

\begin{tabular}{|c|c|}
\hline المدى الزمني في الثانية لطول الآية في سورة العاديات & 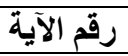 \\
\hline 0.1 .1 & \\
\hline ६.०VA & \\
\hline \&.TVT & \\
\hline ¿.710 & \\
\hline$\varepsilon 79$ & \\
\hline
\end{tabular}

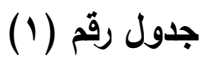




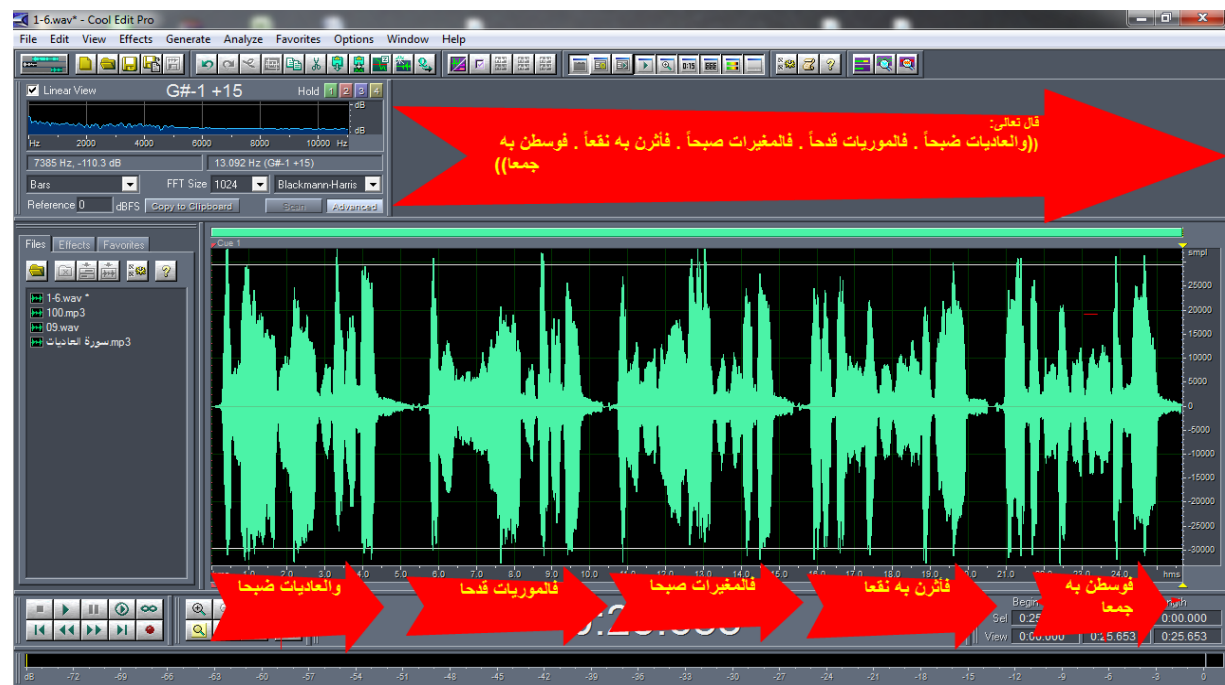

$$
\text { صورة موجية رقم (1)، للآيات (ا-ه) }
$$

الثاني: انسجام الفواصل القرآنية من خلال توافق مددها الزمنية نسبيًا، ممّا اكسبها نغمًا موسيقيًا مؤثرًا يزيد في إبراز المعاني ويقويها. انظر جدول رقم (r) يسجل الاستغراق الزمنّي للفواصل القرآنية للآيات (1-ه)، وانظر صور التحليل الموجي رقم (Y)،(ب)،(ع)،(0)، تنين مدة الفاصلة بين الآيات.

\begin{tabular}{|c|c|}
\hline المدى الزمني في الثانية للفاصلة القر آنية & رقم الآيات التي تقع بينها الفاصلة في سورة العاديات \\
\hline. .0 & $r-1$ \\
\hline $.4 \cdot \Lambda$ & r-r \\
\hline . & $\varepsilon-r$ \\
\hline . & $0 \_\varepsilon$ \\
\hline
\end{tabular}

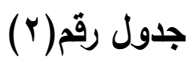

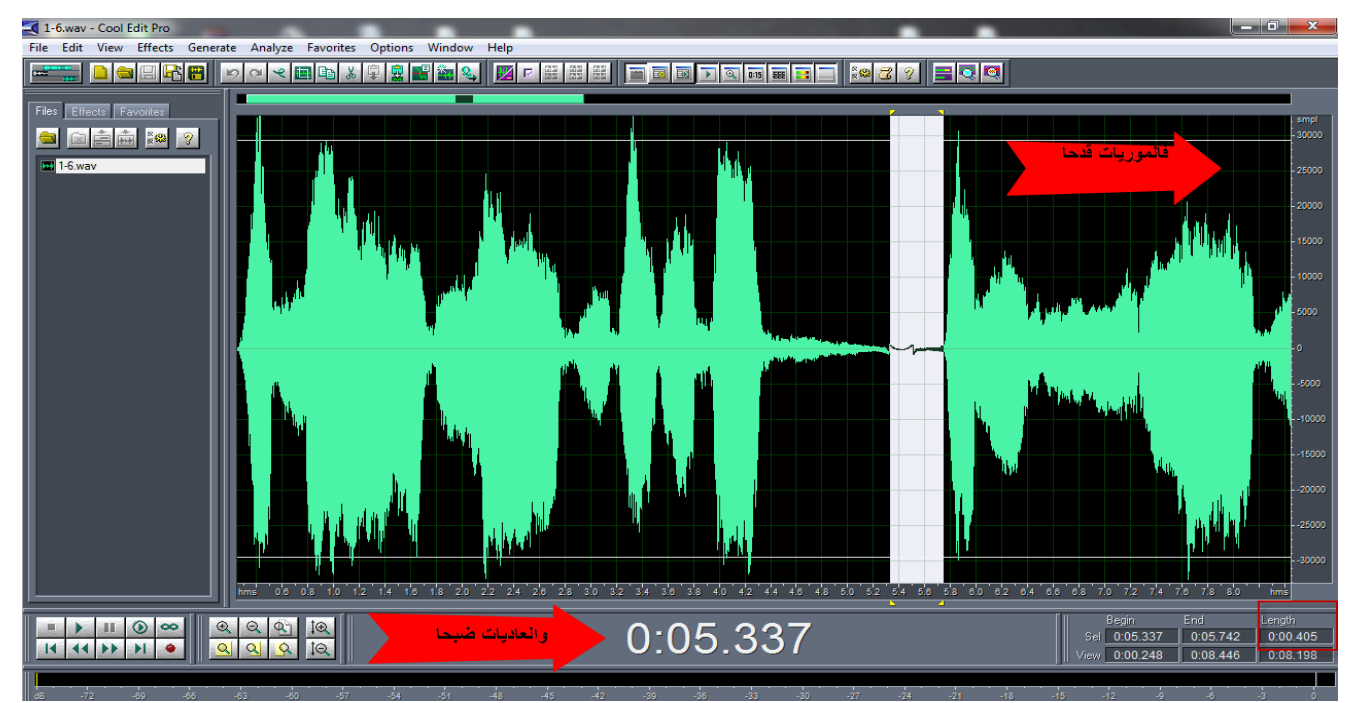

صورة التحليل الموجي رقم (ץ)،الفاصلة رقم(1) 


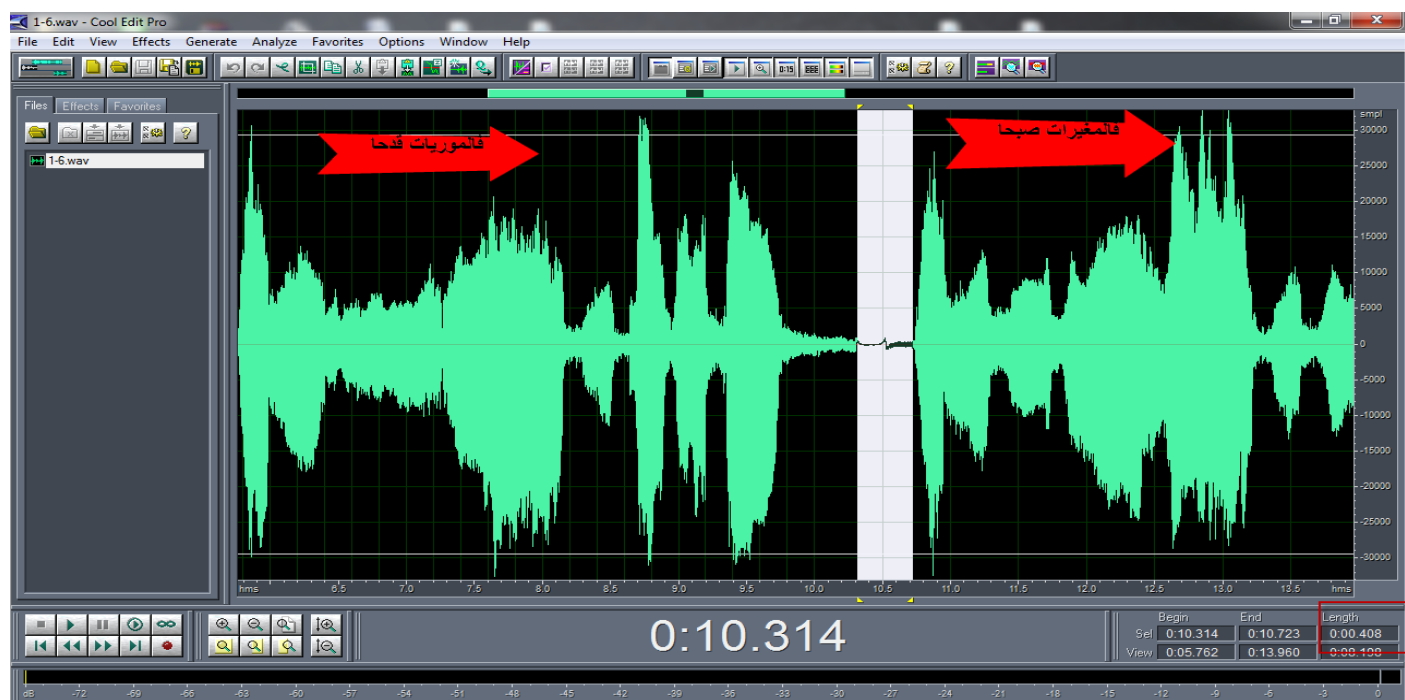

صورة التحليل الموجي رقم(ץ)،الفاصلة رقم(ץ)

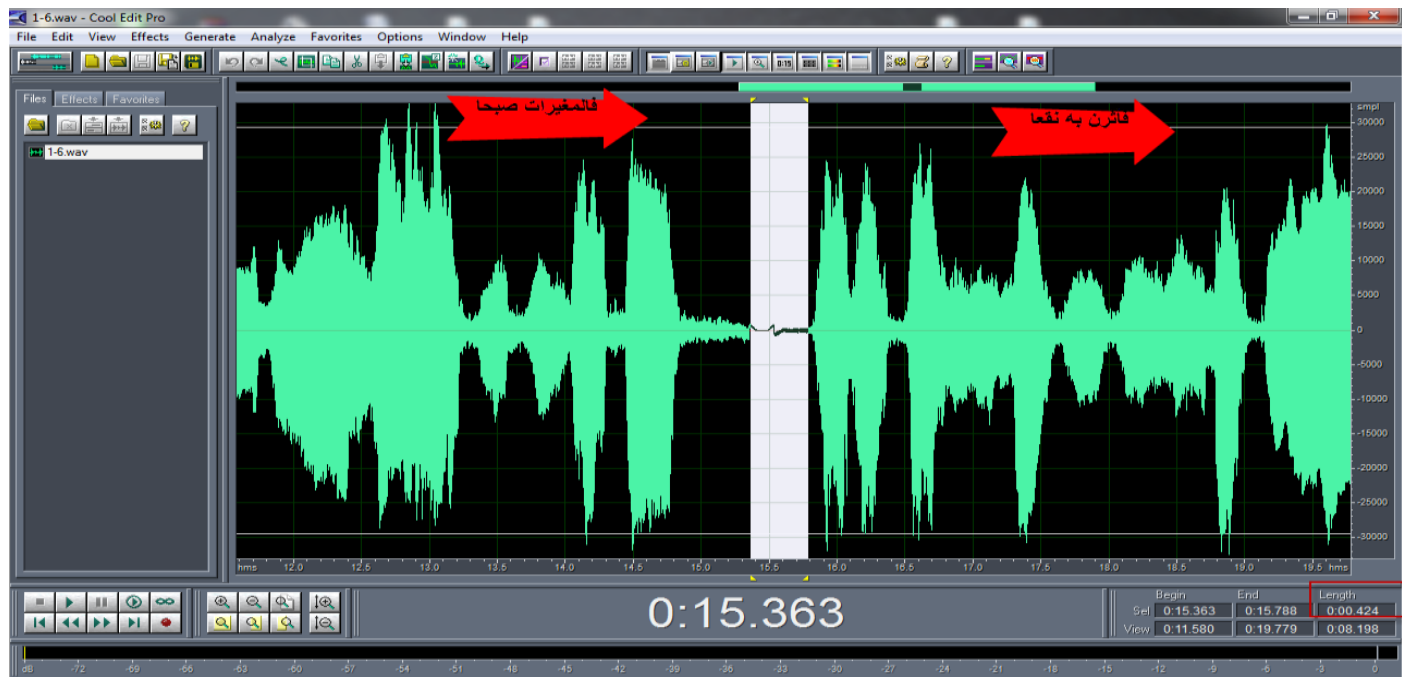

صورة التحليل الموجي رقم (؛)،الفاصلة رقم(؟)

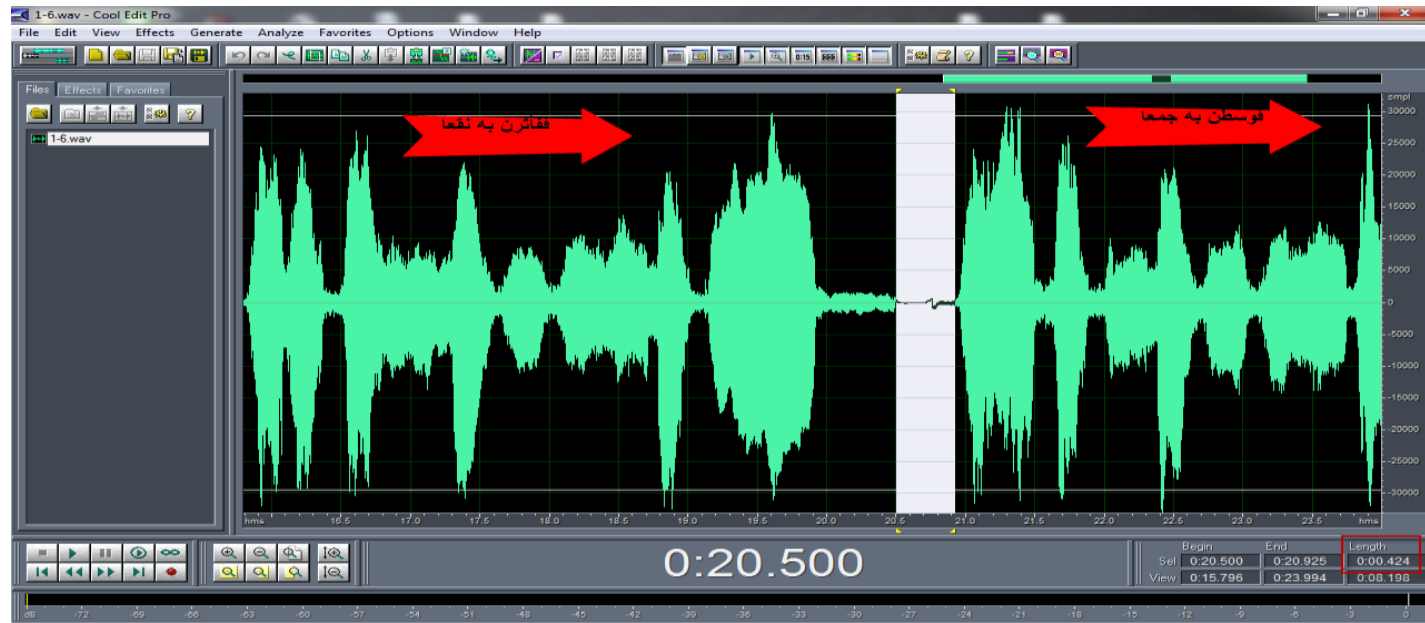

صورة التحليل الموجي رقم(ه)،الفاصلة رقم(؛) 
r- انقسام النمط الموجّي في صورة التحليل الصوتيّ لسورة العاديات على قسمين بينهما فاصلة قرآنية، منلت أطول فاصلة في السورة، انظر جدول رقم(؟)، والصورة الموجية رقم(7)؛ ذلك لأنها

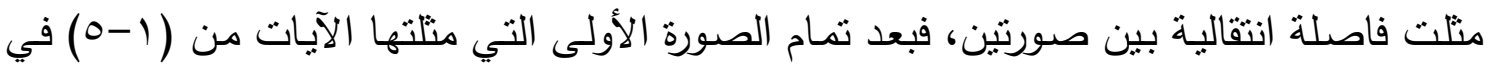

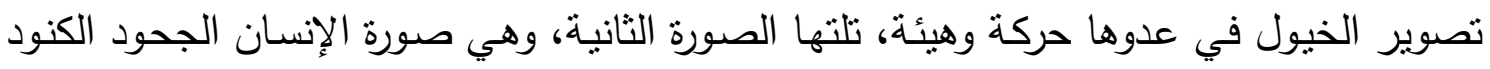

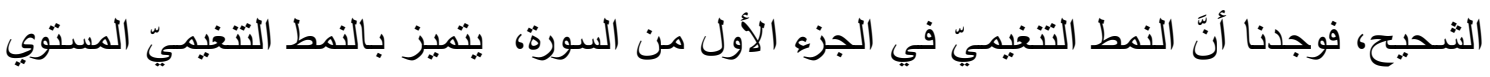

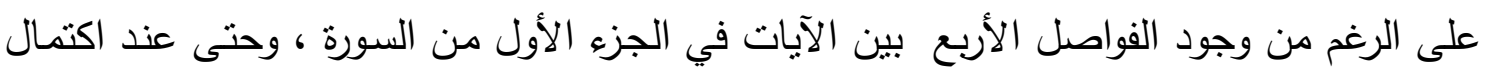

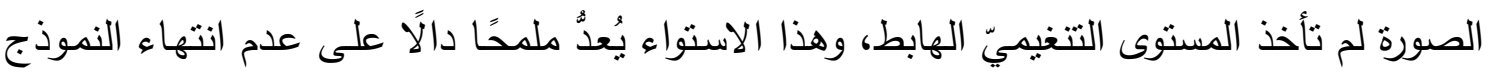

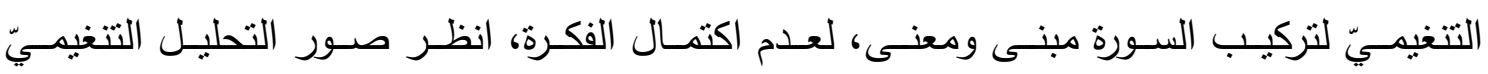

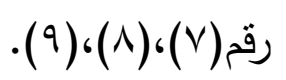

\begin{tabular}{|c|c|}
\hline المدى الزمني في الثانية للفاصلة القر آنية & رقم الآيات التي تقع بينها الفاصلة في سورة العاديات \\
\hline. .0 & $r_{-1}$ \\
\hline 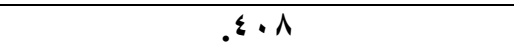 & $r-r$ \\
\hline . $\leqslant$ Y & $\varepsilon_{-} r$ \\
\hline.$\leqslant \leqslant \leqslant$ & $\theta_{-} \varepsilon$ \\
\hline $.79 \mathrm{~V}$ & 7.0 \\
\hline $.0 V \varepsilon$ & $V-4$ \\
\hline$. T \leqslant \pi$ & $\Lambda_{-} \mathrm{V}$ \\
\hline $.7 \cdot 1$ & $9-1$ \\
\hline $.7 \Lambda \varepsilon$ & $1 .-9$ \\
\hline $.9+9$ & $11-1$. \\
\hline
\end{tabular}

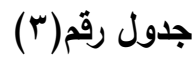

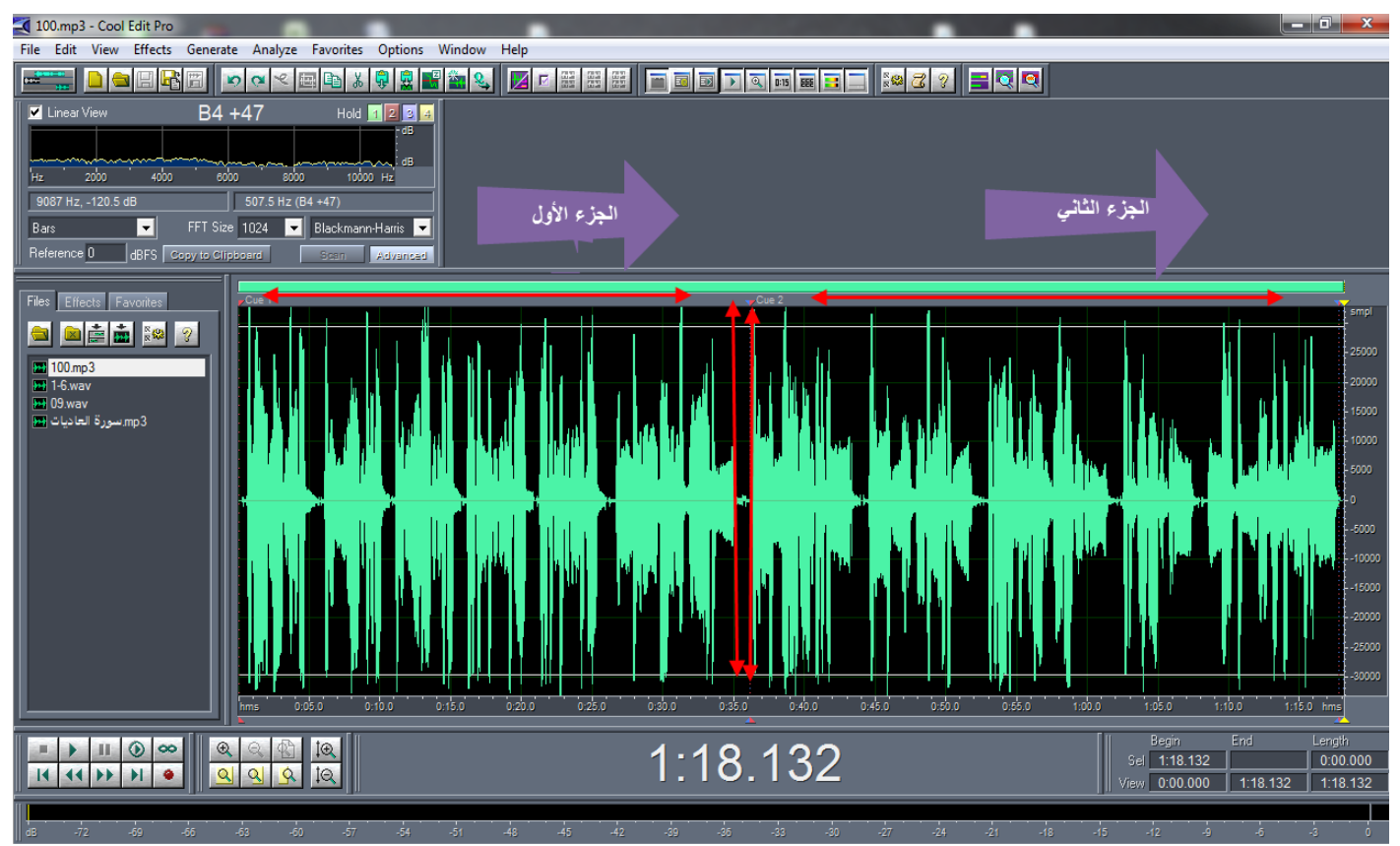

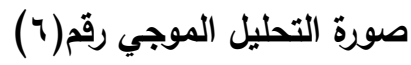




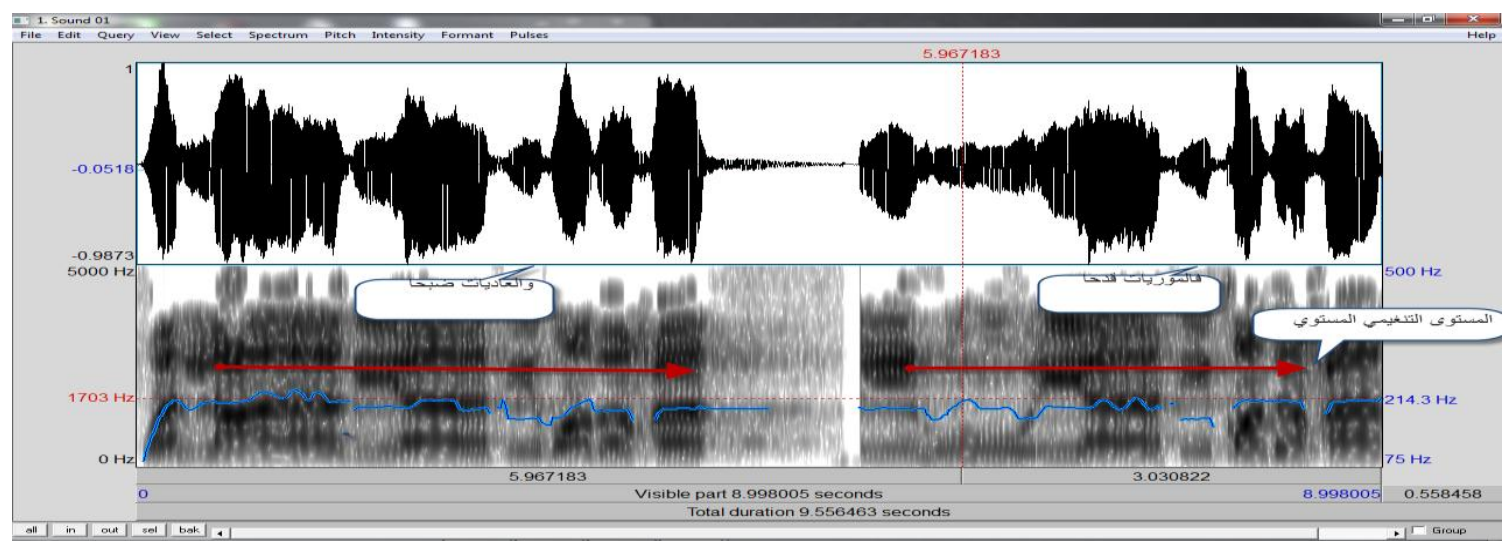

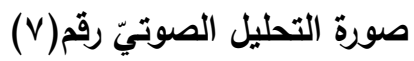

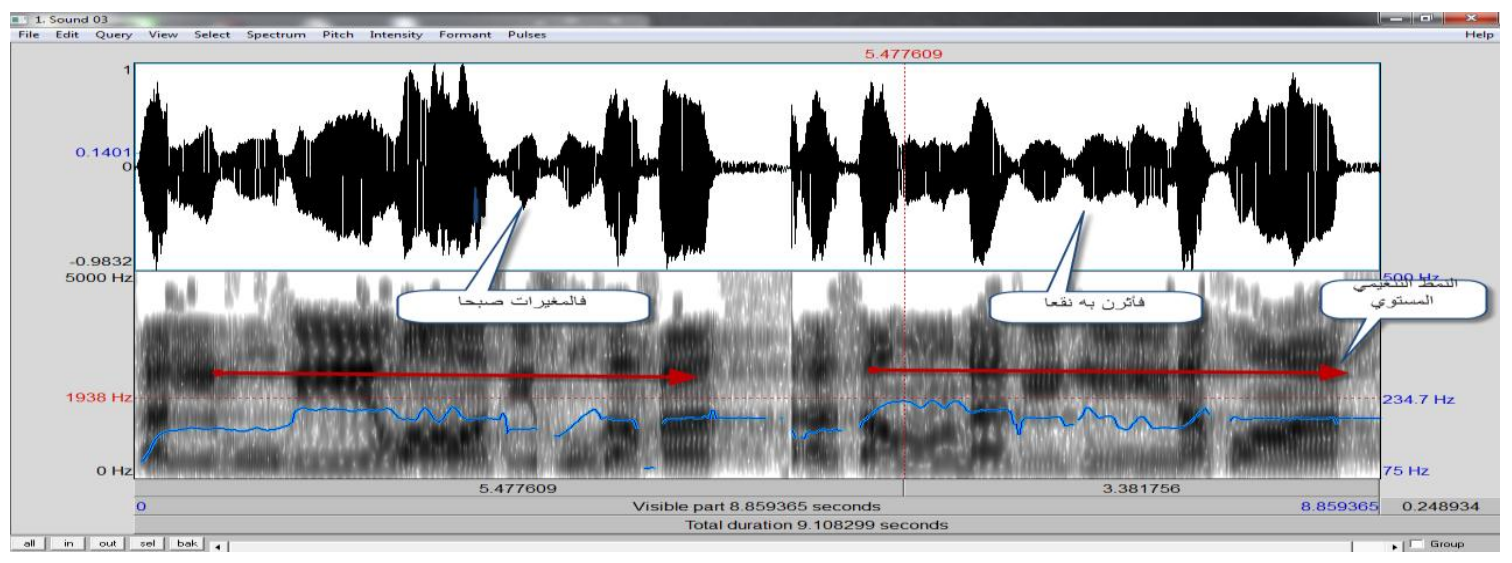

صورة التطليل الصوتيّ رقم(^) - (^)

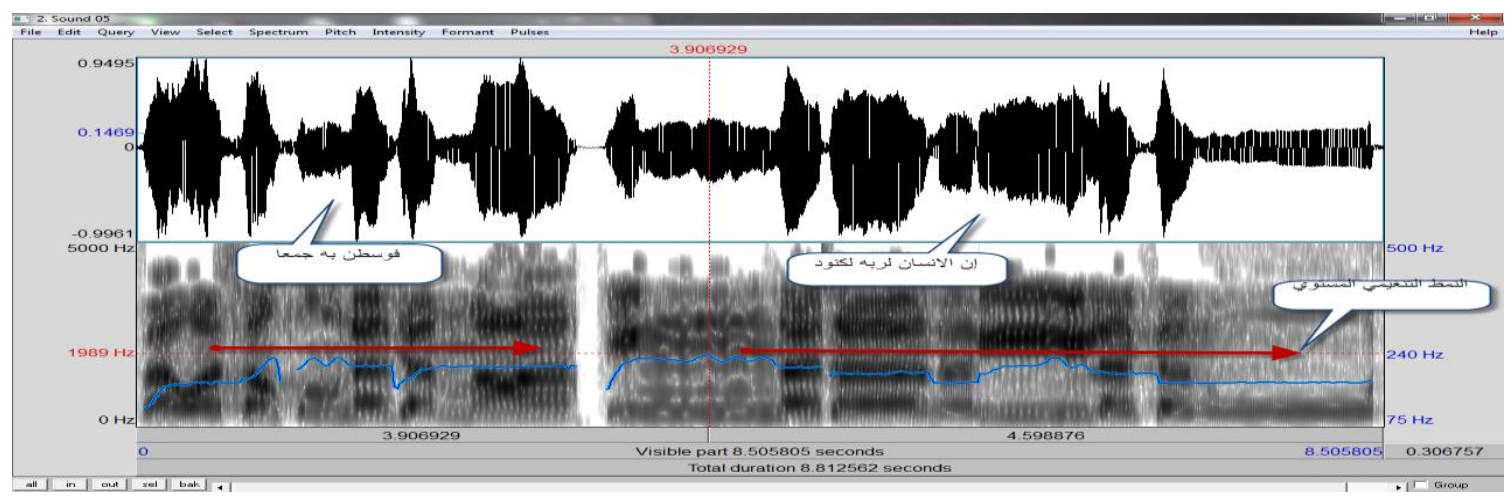

صورة التحليل الصوتيّ رقم(9)

وهذا يُظهر الدور اللغويّ الفعّال الذي تقوم به درجة الصوت، في التعبير عن مستوى التركيب لتمييز نمط تتغيمي معين.

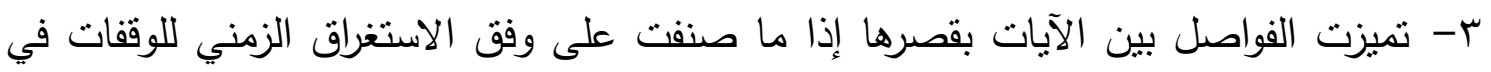

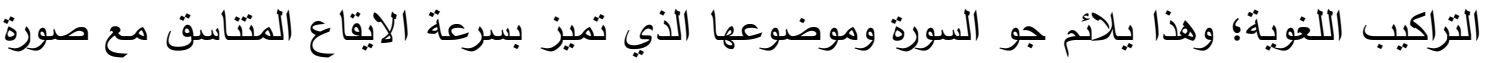

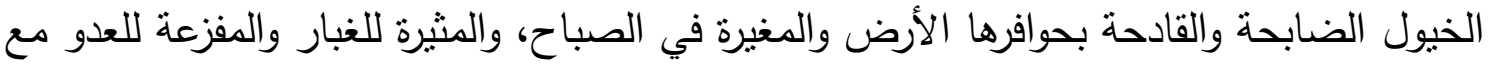
صورة المشبه وهي الإنسان الجحود الكنود الثحيح، إذ الفواصل في التراكيب تجري مجرى 
الأصوات الموسيقية، وتستقر في مواضعها على حسب الحركة والسكون الذي يقتيه المعنى أو السياق العام للسورة. انظر جدول رقم(؟) الذي سجل الاستغراق الزمني لفواصل سورة العاديات. ع- - وبعد هذا النمط التتغيميّ السريع في المطلع، وجوّ السورة، تأتي الخاتمة هادئة مستقرة بعد

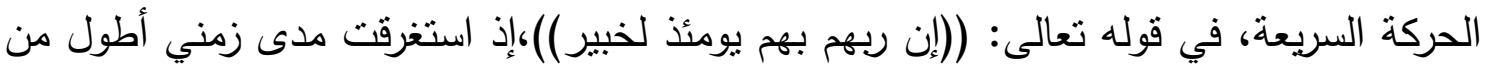

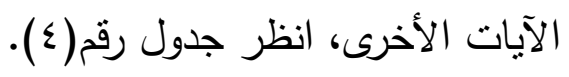

ه-المستوى النغميّ المتوسط، يمضى بعدها المنحني في هبوط نغهيّ على الآية الأخيرة، ليصل

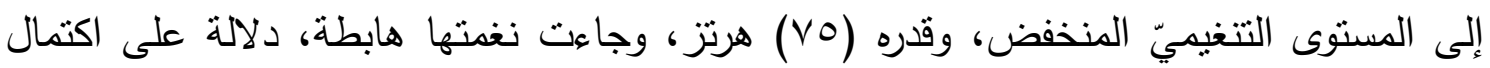
معنى السورة في المبنى والمعنى؛ وبذلك يكون النمط التتغيميّ في السورة يتمنل بالنمط (المستوي -

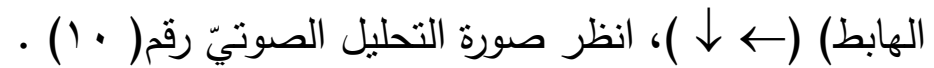

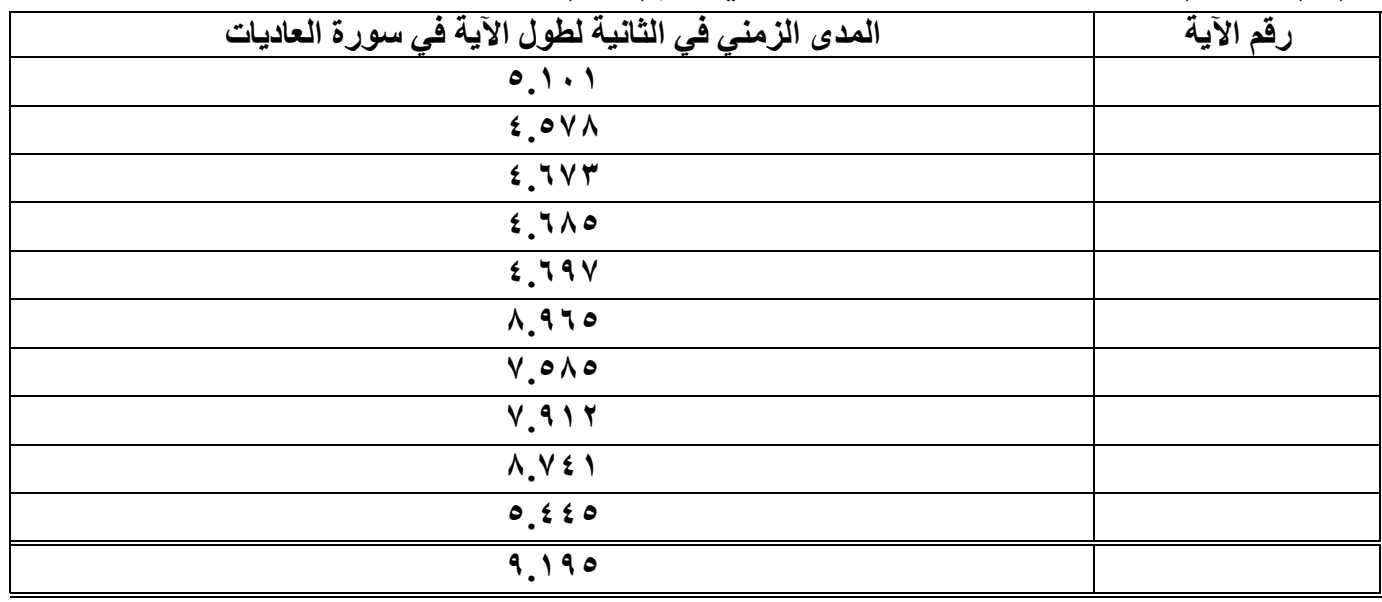

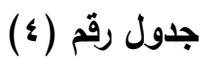

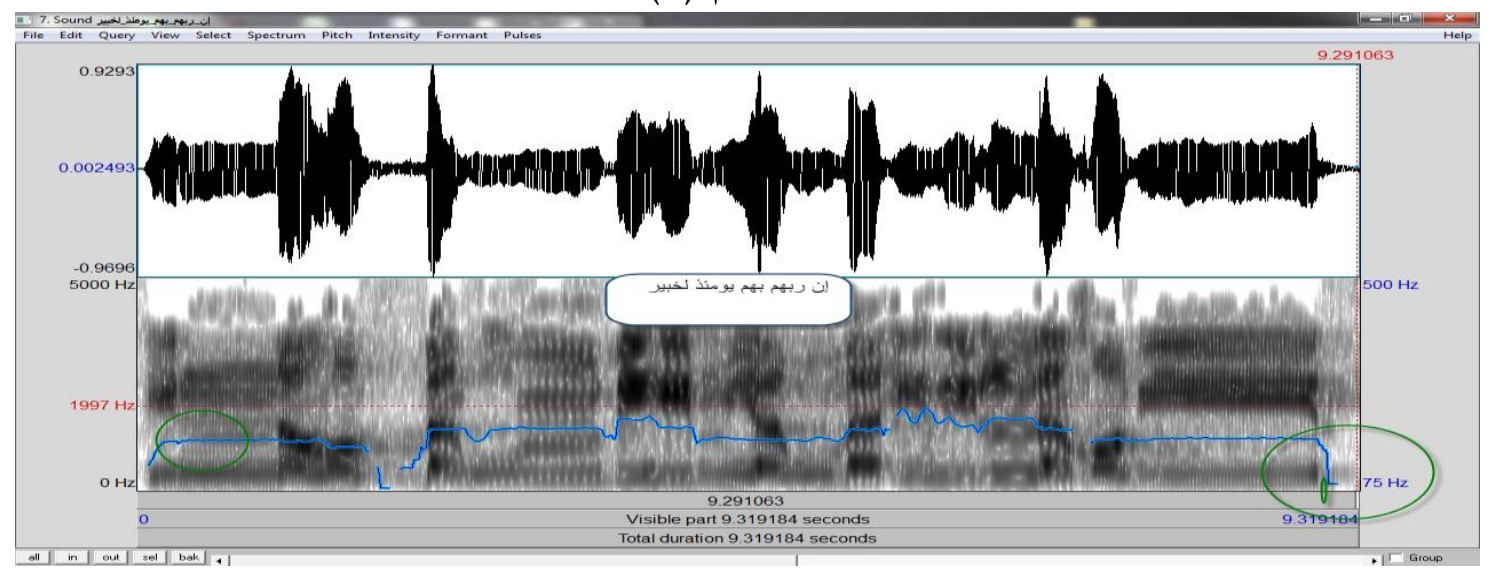

صورة التحليل الصوتيَ رقم (· ) - (1)

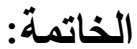

من ذلك ينتيّن أنَّ مفردات العربية في تراكيبها الفنية تتوقف على الاختلاف النغديّ في الأداء،

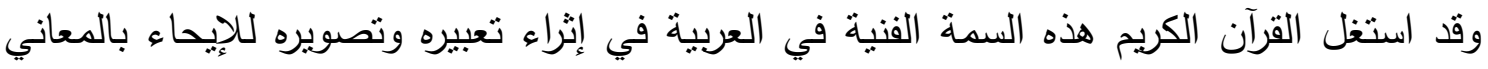
الغزيرة؛ وذلك بتتاسق الوقفات بنغماته وتوقيعاته مع المعنى بكلِّ جزئياته. 
${ }^{(2)}$ Acourse in phonetics, peter Ladefoged, by Harcourt Brace, Jovanovlch, 1975, p. 94.

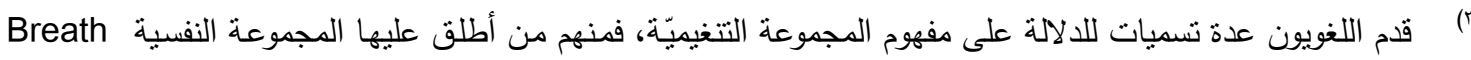
Group وعرفوها، بأنها تتابع نفسي تحدث بدايته ونهايته طاقة النفس التي تحكم الحد الأعلى للطول للجموعة النهات النفسية،

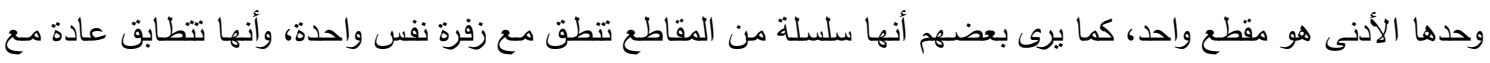

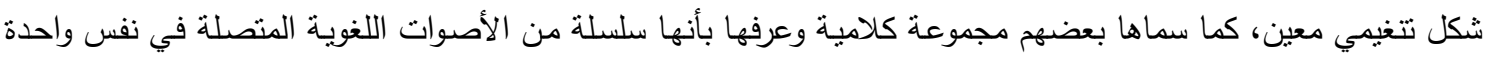

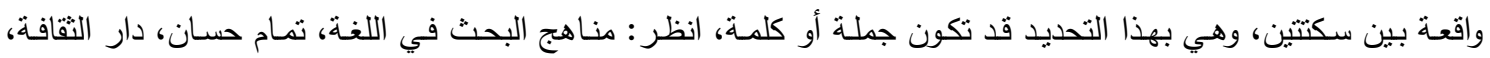

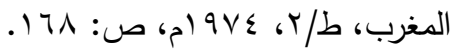

انظر : في الصواته الزمنية، الوقف في اللسانيات الكلاسيكية، مبارك حنون، مطبعة الكرامة - الرباط، دار الأمان،

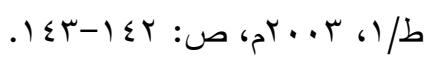

انظر : دراسات في اللسانيات العربية، المشاكلة- التتغيم- رؤى تحليلية، عبد الحميد السيد، دار الحامد للتوزيع والنشر ،

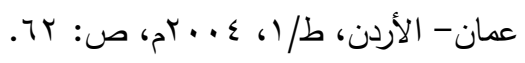

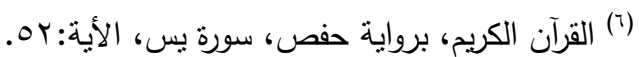

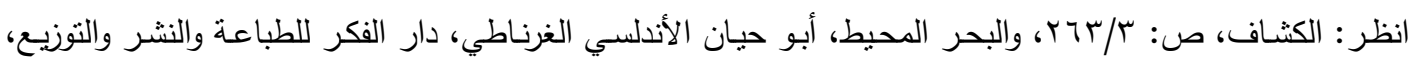

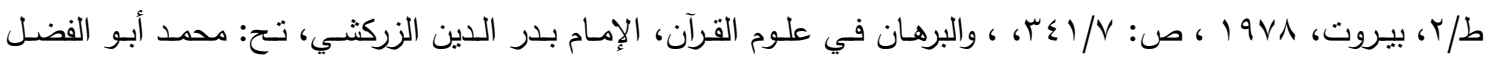

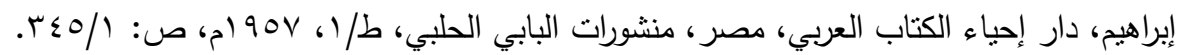

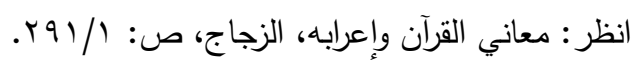

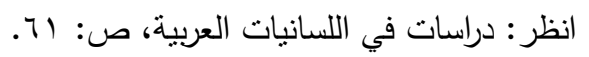

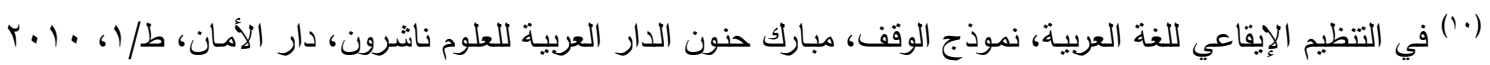
م، ص:79 (19)

(1) انظر : الصوتيّات، برتيل مالمبرج، ترجمة: محمد حلمي هليل، دار عين للدراسات والبحوث الاجتماعية، القاهرة، (د.ط)،

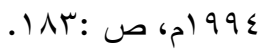

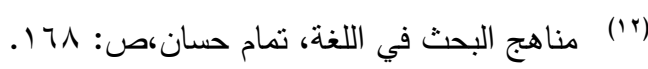

(13) Prosodic system and Intonation in English, David Grystal, Cambridge, hniversity press, 1969, p. 206.

\section{Sources:}

1. General Voices, Arabic voices, Bassam Baraka, National Development Centre,Beirut, (d. T).

2. Methods of research in the language, Tammam Hassan, Dar al-Culture, Morocco, I/II, 1974.

3. In the time periods, the endowment in classical linguistics, Mubarak Hanoon, Al Karama Printing Press-Rabat, Dar al Aman, 1, 2003.

4. Studies in Arabic linguistics, problems-toning-analytical insights, Abdelhamid El Sayed, Dar alHamed for distribution and publishing, Amman-Jordan, 1st, 2004.

5. The surrounding sea, Abu Hayyan al-Andalus al-Granaty, Dar al-Fikr for printing, publishing and distribution, 2nd Floor, Beirut, 1978.

6. The proof in the sciences of the Qur'an, Imam Badreddine Zarkshi, is: Muhammad Abu al-Fadl Ibrahim, Dar al-Arabi, Egypt, Al-Babi al-Halabi Publications, I/I, 1957.

7. In the rhythmic organization of the Arabic language, the Waqf model, Mubarak Hanoon Arab House for Science Publishers, Dar al-Aman, I/1, 2010 CE .

8. audios, Bermbermberg, translation: Mohamed Helmy Hillel, Dar Ain for Social Studies and Research, Cairo, (d. i), 1994. 
